\title{
A AUTO-AVALIAÇÃo NA PRÁTICA PEDAGÓGICA
}

Prof. Dr. Jean-Claude RÉGNIER*

\section{Resumo:}

O presente artigo discute questões relacionadas com a auto-avaliação à luz de práticas educacionais na sala-de-aula. As recomendações pedagógicas para os professores referem-se tanto à necessidade do desenvolvimento da autonomia do aluno pela educação escolar quanto à do desenvolvimento da autonomia do futuro cidadão e do ser humano mesmo. Observando-se que os professores podem fornecer muitos documentos pedagógicos para ajudar na aprendizagem, que contêm exercícios autocorrigidos baseando-se na noção de autocorreção, este artigo propõe discussões sobre o sentido dessas três noções no campo educacional com exemplos práticos.

Palavras-chave: Auto-avaliação, autonomia, autocorreção.

\section{Abstract:}

This article discusses questions related to self-evaluation starting from pedagogical practices in classroom. The educational recommendations to teachers refer both to the need of the autonomy's development by the student by school education and to the development of the autonomy of the citizento-be and the human being itself. Observing that the teachers can provide lots of pedagogical documents to help the learning process, which contains exercices corrected by the student himself based on the concept of selfcorrection, this article seeks to discuss about the meaning of these three concepts on the educational field with practical examples.

Keywords: self-evaluation, autonomy, self-correction.

\section{Introdução}

Um professor estagiário que encontre o termo auto-avaliação pela primeira vez não poderia satisfazer a sua curiosidade buscando o seu significado no Novo Dicionário Aurélio. Pois, se o termo avaliação figura, não aparece nenhuma referência relacionada a ele. Não obstante, a citação seguinte marca a sua presença no campo pedagógico: “Desenvolver um portfólio nos moldes como estamos concebendo envolve refletir constantemente sobre o

\footnotetext{
* Université Lumière Lyon-2 - FRANÇA
} 
progresso do aluno e, por sua vez, o aluno com oportunidade de participar da organização do seu material reflete sobre o que nele está contido, ou seja, auto-avalia-se"1.

Nessa perspetiva surgem ao menos as duas questões seguintes:

- qual é o sentido que se poderia atribuir ao termo auto-avaliação?

- quais são as crenças e os conhecimentos que fundamentam a prática pedagógica da auto-avaliação?

Apoiando tanto sobre a experiência duma prática pedagógica na salade-aula no ensino da matemática e da estatística, quanto sobre várias pesquisas, tentamos fornecer alguns elementos de respostas a essas questões.

\section{Quepoderia ser a auto-avaliação?}

Uma exploração mesmo sucinta do campo semântico do termo autoavaliaçã orequer a identificação de rede de noções às quais ele pode estar ligado. O esquema abaixo visa a explicitação dessa rede.

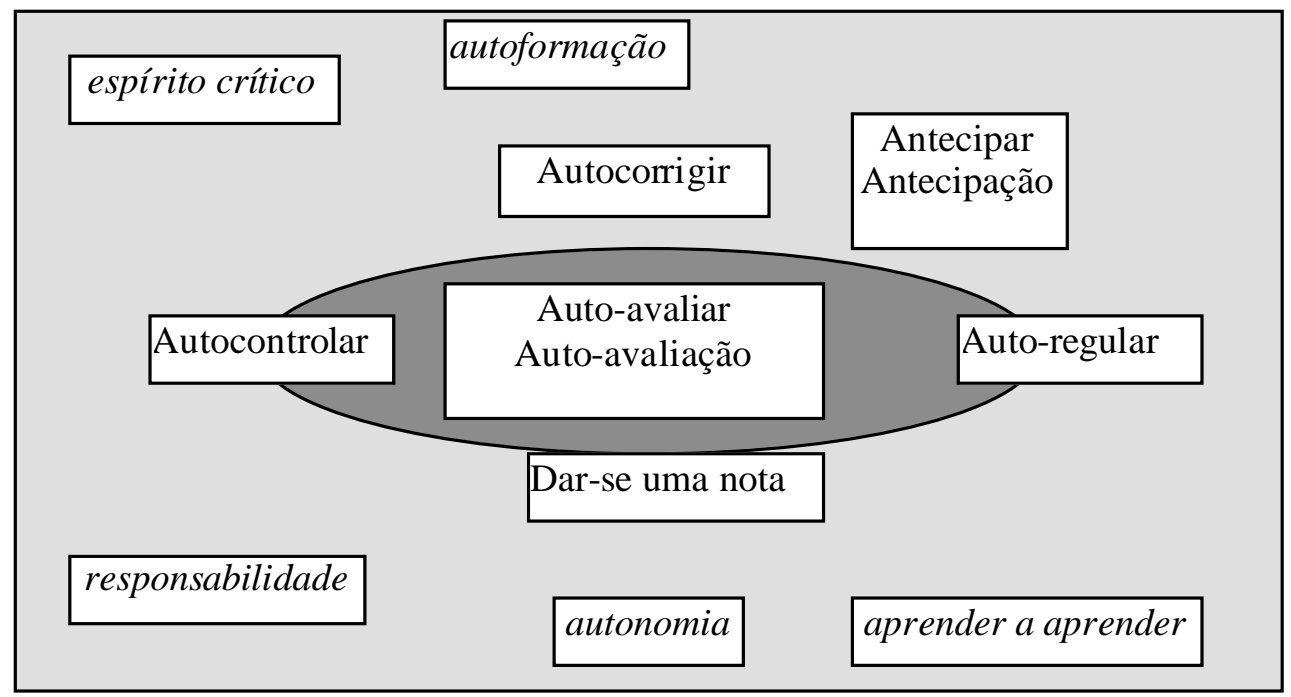

[ esquema1]

O uso da noção auto-avaliação não pode ser separado da avaliação e do questionamento fundamental desse procedimento no meio escolar ou universitário resumido na tabela a seguir. 


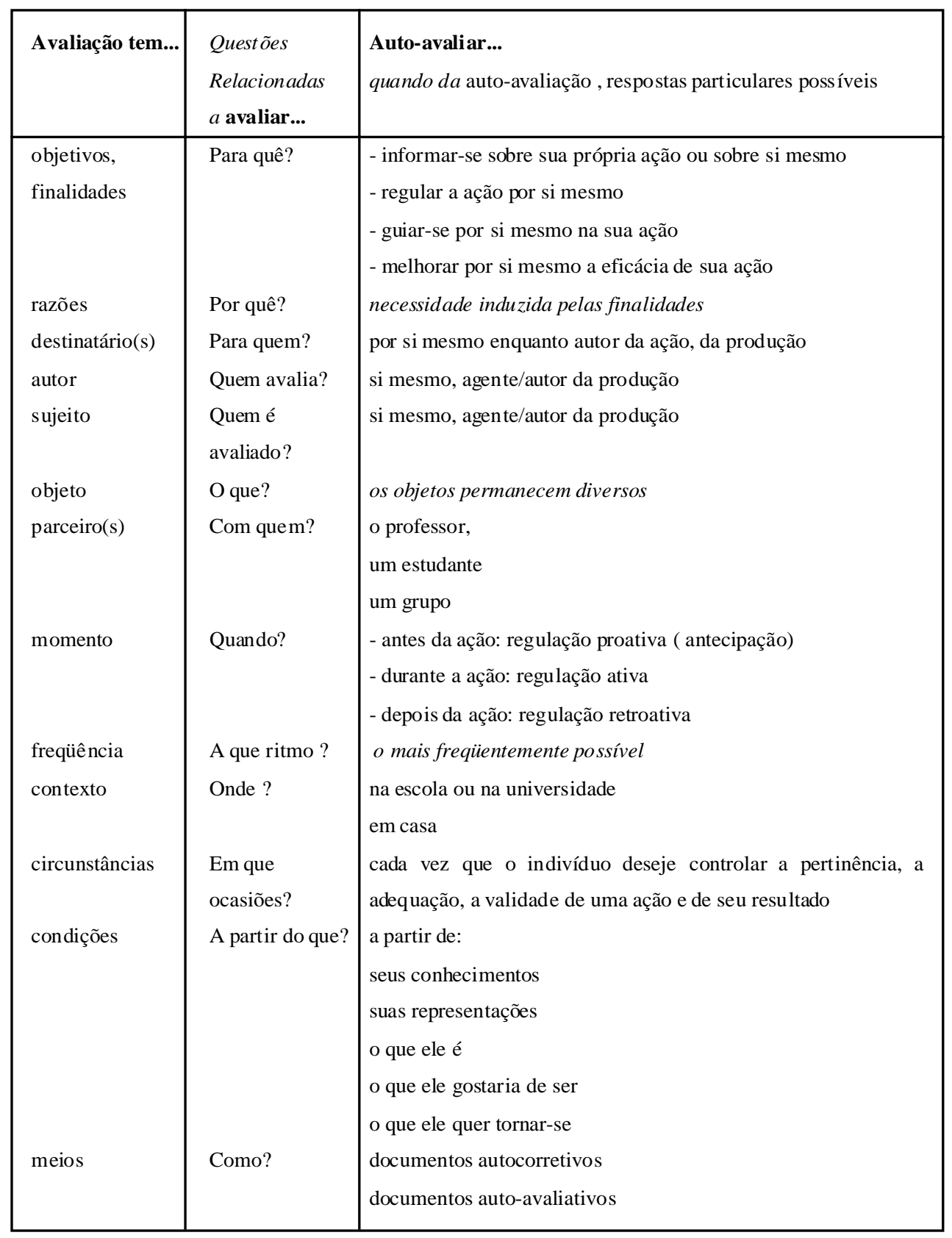


A noção de avaliação pode receber várias definições cujo significado usual é o de operação para fazer a apreciação, para julgar, para determinar o valor de uma ação, uma produção ou uma performance. Não obstante, nós preferimos a definição dada por $\mathrm{DE} \mathrm{KETEIE}^{2}$ : avaliação como procedimento que consiste em recolher um conjunto de informações pertinentes, válidas e confiáveis para após examinar o grau de adequação entre este conjunto de informações e um conjunto de critérios escolhidos adequadamente para fundamentar tomada de decisão. Ela traduz em parte as práticas de avaliação que nós utilizamos.

Para melhor esclarecimento, somos levados a distinguir as três noções seguintes:

[esquema2]

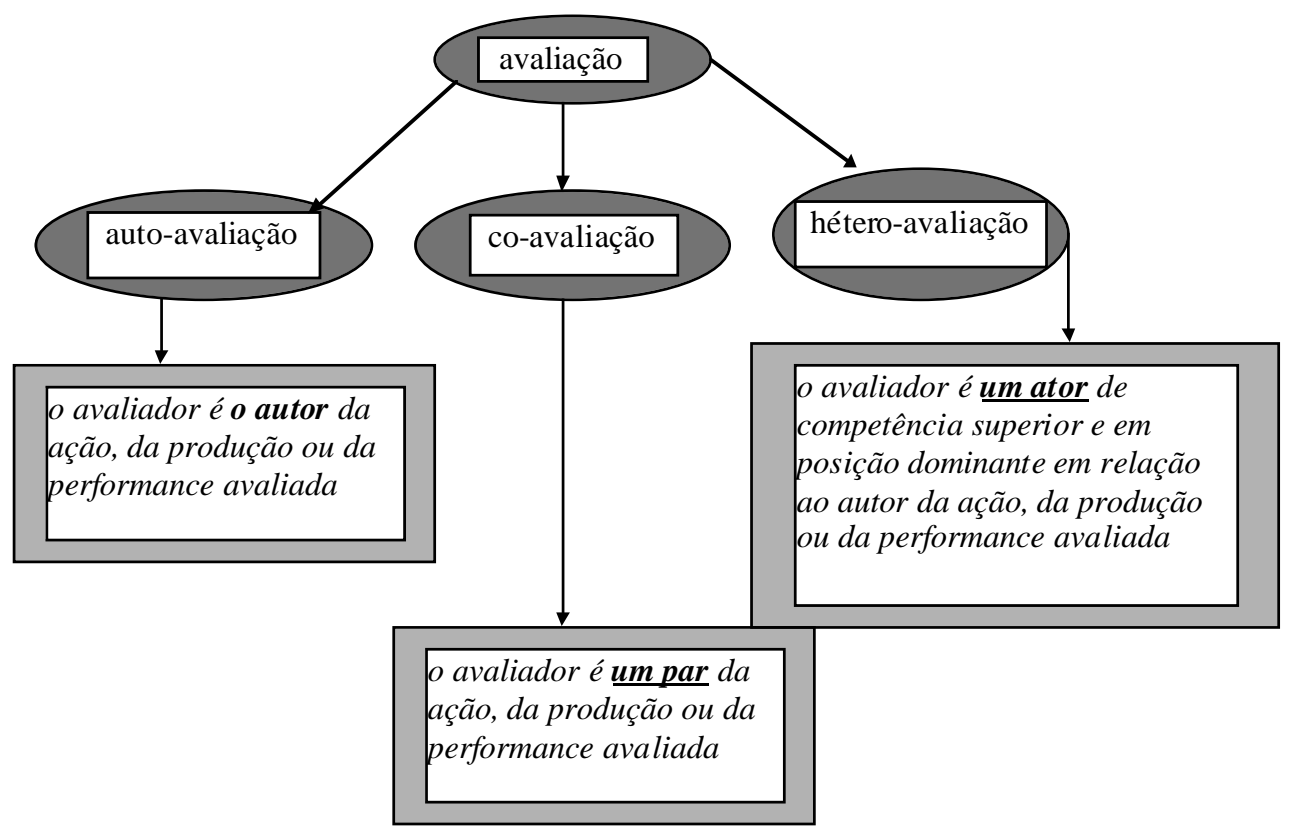

Observe-se que essas noções foram concebidas de forma complementar e que não desejamos impor a primazia de uma com relação às outras. Para ilustrar essa idéia poderíamos dizer que:

hétero-avaliativo;

- falar de capacidade a se auto-avaliar requer um procedimento

- para se auto-analisar e auto-analisar sua ação didática e pedagógica, o professor se apóia em informações oriundas de práticas hétero-avaliativas;

- a hétero-avaliação pelo professor ou a co-avaliação por um ou 
por vários alunos das produções de um aluno trazem a este último uma informação de retorno que ele pode reinvestir na sua ação auto-avaliativa,

- a auto-avaliação desempenhando um papel de avaliação diagnóstica traz informações que permitem ao aluno preparar-se de uma certa forma à hétero-avaliação de fim de seqüência didática ou de fim de ciclo de estudos.

Poderíamos assim propor uma primeira definição de auto-avaliação como sendo um processo pelo qual um indivíduo avalia por si mesmo, e geralmente para si mesmo, uma produção, uma ação, uma conduta da qual ele éo autor, ou ainda suas capacidades, seus gostos, suas performances e suas competências ou a si mesmo enquanto totalidade.

Enunciada dessa forma, essa definição se coloca em um nível de generalização mais amplo. Parece-nos que não importa que ser humano teria dificuldades a escapar de uma operação dessa natureza.

Em situação de formação escolar ou universitária, em particular, quando essa formação implica adolescentes ou adultos e diz respeito a matemática ou a estatística, poderíamos esclarecer alguns pontos.

A auto-avaliação é um processo cognitivo complexo pelo qual um indivíduo (aprendiz ${ }^{3}$, professor ${ }^{4}$ ) faz um julgamento voluntário e consciente por si mesmo e para si mesmo, com o objetivo dum melhor conhecimento pessoal, da regulação de sua ação ou de suas condutas, do aperfeiçoamento da eficácia de suas ações, do desenvolvimento cognitivo. Este julgamento é realizado:

- sobre ele mesmo, independentemente de toda tarefa precisa a ser realizada no momento e se situa com relação a um campo disciplinar (matemática, estatística). Neste caso específico, encontramos fatores do tipo:

- o gosto pela matemática e pela estatística;

- o gosto pelos raciocínios que elas subentendem;

- as possibilidades pessoais para alguns tratamentos que, em graus variados, integram a fiabilidade e a certeza do raciocínio, a imaginação, 0 cuidado, a disponibilidade, o investimento, o desejo de conhecer, de aprender, de compreender ou de comunicar, de explicar, de partilhar ...

- a identificação e a expressão das dificuldades pessoais encontradas na resolução de certos problemas, na aprendizagem e compreensão de certas noções, certos métodos, conceitos, teoremas;

- sobre si mesmo e em geral se situando com relação aos outros (aprendizes e professores);

- sobre sua própria avaliação e os progressos realizados durante 0 percurso de formação;

- sobre sua própria progressão numa situação de aprendizagem determinada por um objetivo e centralizada sobre um conteúdo em relação à matemática e à estatística;

- sobre o seu domínio de certas noções, conceitos e métodos; 
- sobre sua capacidade a mobilizar noções, conceitos, teoremas e métodos para responder a uma questão do domínio da matemática ou da estatística, ou para resolver um problema de matemática ou de estatística;

- sobre a adequação entre os objetivos previstos e a produção realizada no quadro de uma tarefa a cumprir;

- sobre a adequação e a pertinência de um tratamento acionado na resolução de um problema de matemática ou de estatística ou sobre a validade da ou das soluções propostas.

Este processo se manifesta por uma conduta de auto-avaliação que 0 indivíduo aciona e administra por si mesmo. Aliás, nós não podemos esquecer que o termo auto-avaliação evoca tanto o resultado quanto o processo. situações:

Do ponto de vista da nossa prática, gostaríamos de precisar quatro

- a auto-avaliação a priori:

essa situação corresponde, por exemplo, àquela onde o indivíduo (aprendiz) avalia uma capacidade sem uma produção explícita de sua parte que poderia ser hétero-avaliada, oferecendo assim uma informação de controle externo. Essa auto-avaliação realiza-se com um tempo de antecipação. Um momento adequado pode se situar exatamente antes de um teste de fim de seqüência didática para avaliar a aprendizagem;

- a auto-avaliação concomitante com ou sem referência externa:

essa situação corresponde, por exemplo, àquela onde o indivíduo aprendiz avalia paulatinamente sua produção. Ela se realiza no tempo da execução da tarefa. Pode ser assistida ou não por um documento de ajuda. A atividade pode ser exercida durante um teste de fim de seqüência didática avaliando-se a aprendizagem por uma grade de avaliação fornecida.

- a auto-avaliação a posteriori sem referência externa:

essa situação corresponde, por exemplo, àquela onde o indivíduo aprendiz avalia sua produção após um teste de fim de seqüência didática que avalia a aprendizagem;

- a auto-avaliação a posteriori com referências externas:

essa situação corresponde, por exemplo, àquela onde o indivíduo aprendiz avalia sua produção após um teste de fim de seqüência didática que avalia a aprendizagem, utilizando um documento autocorretivo e eventualmente informações trazidas pelos pares e mesmo pelo professor.

Precisaremos agora os três outros termos da rede que ocupam um lugar importante na explicitação da noção de auto-avaliação.

A auto-notação diz respeito ao procedimento que consiste na atribuição de uma nota pelo próprio aprendiz, dentro do quadro adotado pelo sistema escolar, a partir das regras estabelecidas pelo professor ou mesmo pelo aprendiz. Se a introdução desse procedimento pedagógico na classe traduz uma reconsideração do lugar do aluno na situação de ensino, ela não 
retifica por isso os defeitos da notação que os trabalhos docimológicos ${ }^{5}$ contribuíram amplamente a explicitar. Isto se reflete mesmo na validade dos resultados dessa autonotação. Na realidade, sabendo-se o quanto a flutuação de notas é importante entre avaliadores expertos, podemos interpretar tanto a variação entre os valores propostos pelo aluno quanto aqueles propostos pelo professor. Aliás, não haveria um risco de confundirmos a capacidade para a autonotação e a capacidade a se conformar aos hábitos de notação do professor. Não daremos continuidade aqui a essa discussão na medida em que não consideramos como pertinente o uso da notação usual (sobre 10 ou sobre 20) quando esses números codificam apenas numericamente uma variável qualitativa que é tratada sem nenhum escrúpulo como uma variável quantitativa, calculando-se uma média ${ }^{6}$.

$\mathrm{O}$ autocontrole ${ }^{7}$ recobre tanto a idéia de um processo cognitivo integrado ao processo auto-avaliativo e a idéia de uma conduta conscientemente adotada pelo indivíduo que deseja se desligar da tutela de um mestre e que consiste em se assegurar, por si mesmo e por meios adequados e explícitos, da pertinência, da adequação de um método escolhido e da validade dos raciocínios aferentes para resolver um problema, da verossimilhança ou da exatidão de uma resposta oriunda da aplicação desse método, da pertinência ou da validade de uma interpretação dessa resposta. Fichas-guias podem constituir suportes concretos desses meios. Na perspectiva de uma formação do espírito científico, pode-se considerar a aquisição e o desenvolvimento do hábito e da capacidade de se autocontrolar como um dos objetivos do ensino da matemática e da estatística. Um material pedagógico adaptado tal qual os autotestes ou livros autocorretivos concretiza um dos meios aos quais o indivíduo pode recorrer, para desenvolver esta capacidade ou instalar esse hábito.

A autocorreção recobre igualmente a dupla idéia de um processo cognitivo integrado ao processo auto-avaliativo e de uma conduta conscientemente adotada pelo indivíduo desejoso de se desligar da tutela de um professor, e que consiste por meios adequados e explícitos em retificar por si mesmo um resultado, o raciocínio pelo qual ele foi produzido ou o método escolhido para conduzir o raciocínio e produzir o resultado, mas também para retificar, melhorar ou reforçar os conhecimentos (saber, saber-fazer, saber ser) a partir das informações recolhidas para o autocontrole. Na perspectiva de autoformação, pode-se considerar a aquisição e o desenvolvimento do hábito e da capacidade de aprender. Um material pedagógico adaptado, tal como os livretos autocorretivos e particularmente aqueles elaborados com certos critérios estudados em nossos trabalhos ${ }^{8}$ concretizam um meio pelo qual o indivíduo pode recorrer a uma prática autocorretiva.

Nós não poderíamos concluir sem evocar a idéia de autonomia que orienta de uma forma determinante tanto nosso discurso sobre auto-avaliação quanto nossa prática pedagógica. 
J. Leif ${ }^{9}$ define a autonomia como a capacidade do ser humano que lhe permite se determinar segundo as normas de sua própria reflexão e de sua própria vontade. Ela se manifesta pela independência da conduta, sendo esta última regida conforme regras e imperativos que o sujeito se impõe a si mesmo, por livre escolha. De modo quase unânime, esta capacidade de autonomia é colocada como uma das finalidades do processo educativo. Entretanto, apesar do discurso pedagógico que defende a importância da ação, e da unanimidade a respeito da finalidade, a discordância permanece quanto aos meios para desenvolver a autonomia do aluno. Do nosso ponto de vista pedagógico, o desenvolvimento da autonomia do aluno é construído mediante sua própria experiência prática da autonomia em sala de aula. Além disso, mas permanecendo-se numa perspectiva praxeológica, nós constatamos a relatividade e a variabilidade desta capacidade no indivíduo em função do contexto e da época da sua vida ou de um estado físico ou psíquico. Os exemplos são múltiplos nessa área. Assim, parece-nos importante falar sobretudo de uma autonomia relativa, isto é, do grau de autonomia em relação a um contexto e a uma conduta a adotar neste contexto.

No quadro particular do ensino e da aprendizagem da matemática e da estatística no segundo grau ou na universidade, nós distinguimos dois eixos:

- autonomia do aluno, sujeito que está aprendendo, face ao professor, sujeito que está ensinando.

Na tabela seguinte aparecem seis níveis de autonomia

\begin{tabular}{|c|c|c|c|}
\hline & & $\begin{array}{c}\text { Assunção da } \\
\text { responsabilidade do } \\
\text { aluno com relação à } \\
\text { tarefa é... }\end{array}$ & \\
\hline $\begin{array}{l}\text { Contribuição do } \\
\text { professor é... }\end{array}$ & $\begin{array}{l}\text { estimada possível } \\
\text { com conseqüências }\end{array}$ & $\begin{array}{c}\text { estimada possível } \\
\text { sem nenhuma } \\
\text { conseqüência }\end{array}$ & estimada impossível \\
\hline estimada necessária & $\begin{array}{l}\text { autonomia } \\
\text { nível } 4\end{array}$ & $\begin{array}{l}\text { autonomia } \\
\text { nível } 2\end{array}$ & $\begin{array}{l}\text { autonomia } \\
\text { nível } 6\end{array}$ \\
\hline estimada supérflua & $\begin{array}{l}\text { autonomia } \\
\text { nível } 3\end{array}$ & $\begin{array}{l}\text { autonomia } \\
\text { nível } 1\end{array}$ & $\begin{array}{l}\text { autonomia } \\
\text { nível } 5\end{array}$ \\
\hline
\end{tabular}

Observe-se que não consideramos aqui a recusa sistemática e categórica do professor por parte do aluno como sendo uma manifestação positiva de sua autonomia em relação ao professor. Esta tabela colocou em evi- 
dência sobretudo seis situações pedagógicas nas quais um aluno pode se encontrar para manifestar sua autonomia perante o professor:

- autonomia do aluno face ao conhecimento do domínio disciplinar estudado.

Neste eixo, consideramos as várias possibilidades de obter informações escritas, de mobilizar conhecimentos para transferi-los a uma nova situação encontrada, e enfim de argumentar a partir de conhecimentos em uma confrontação com observações ou com indivíduos. Assim, numa nova situação-problema, a autonomia do aluno se manifesta por seu engajamento a se confrontar com a resolução e a ultrapassar o obstáculo imposto, a partir dos conhecimentos adquiridos, mediante a busca e a análise de seus erros.

Algumas condutas explícitas podem ilustrar este fenômeno, tais como o fato de buscar informações num livro de matemática ou no seu caderno, bem como, colocar questões pertinentes ao professor, percebido nesse momento como pessoa-recurso.

Obviamente a capacidade de auto-avaliação constitui um componente da autonomia do aluno perante o professor e perante o domínio disciplinar. Nós conjeturamos mesmo que o desenvolvimento da capacidade de auto-avaliação favorece o desenvolvimento da autonomia do aluno.

\section{Quais são as crenças e os conhecimentos quefundamentama prática pedagógica da auto-avaliação?}

Um artigo da Revista da $\mathrm{ADMEE}^{10}$ foi destinado a um debate sobre a auto-avaliação. Enquanto coleta de informações que permitem uma regulação da ação, a auto-avaliação é considerada como um processo cognitivo que apoia toda conduta. Do nosso ponto de vista, nós consideramos que a autoavaliação é um dos determinantes do desenvolvimento cognitivo individual. Portanto, desenvolver a capacidade de se auto-avaliar influi na capacidade de aprender.

LAVEAULT e FOURNIER ${ }^{11}$ tentaram relacionar os processos de antecipação, de preparação e de auto-avaliação antes de um exame final escolar no Canadá. Eles constataram que a antecipação das exigências conduz a uma melhor preparação dos alunos para as provas. Entretanto, eles não conseguiram relacioná-la à auto-avaliação realizada no momento mesmo das provas. Enfim, eles estabeleceram uma ligação forte entre a auto-avaliação e a performance ao exame. Confirmando o papel da auto-avaliação no seio do processo de regulação da aprendizagem, eles escreveram:

Para estar em medida de saber se ele não entendeu, de conhecer se ele ainda está longe da solução, de avaliar se a estratégia empregada é a boa 
ou de decidir se ele precisa de ajuda ou de informações suplementares, de escolher entre várias partes da disciplina a preparar, o aluno deve ser capaz de controlar os seus próprios mecanismos cognitivos (...). O controle pelo aprendiz dos seus próprios processos de aprendizagem influi na conscientização e no funcionamento destes processos, (isto é) a metacognição.

FONTAINE e TRAHAN ${ }^{12}$ identificaram duas categonias de crenças perante a auto-avaliação do aprendiz na escola básica. A primeira reúne as pessoas que acreditam na importância e na utilidade desse processo - "o aluno deveaprender a identificar suas forças e suas fraquezas" -, enquanto que a segunda reúne as que afirmam a impossibilidade - "o aluno é muito jovem para conseguir identificálas".

Duboux ${ }^{13}$ tentou evidenciar que a prática auto-avaliativa constitui-se como uma prática que favorece a motivação dos alunos para matemática. O dispositivo pedagógico utilizado nessa pesquisa baseou-se no nosso trabalho sobre esse tema ${ }^{14}$ e prolongou-se durante todo ano escolar. Ele conclui que a pesquisa não permitiu verificar o efeito da auto-avaliação sobre a motivação. Porém, a prática da autoavaliação permitiria aos alunos um momento de reflexão, de análise e de tomada de consciência das motivações de seus comportamentos, sobretudo as que dizem respeito à matemática.

BARBIER $^{15}$ relata algumas pesquisas que mostram que a atitude de um sujeito diante duma tarefa se modifica quando, depois de tê-la começado, ele procede a uma auto-avaliação, e mesmo que ele é mais motivado para retomar suas tarefas ou para realizar outras mais difíceis.

Comparando práticas da auto-avaliação e da hétero-avaliação, MAEHR e STALNGS ${ }^{16}$ observaram um efeito positivo sobre a motivação dos alunos e um maior interesse por tarefas difíceis quando a auto-avaliação é praticada. Mas nenhuma diferença significativa é constatada sobre o desenvolvimento das performances e das competências dos alunos.

Mc LAUGHLiN ${ }^{17}$ chama a atenção sobre os limites das práticas autoavaliativas. Ele afirma que, de um lado, os alunos têm tendência a sobrestimar as suas performances e a baixar progressivamente as exigências das nomas requeridas para obter melhores resultados. De outro lado, os alunos devem adquirir conhecimentos, ser ajudados e guiados para serem conduzidos progressivamente a organizarem por si mesmos suas situações de aprendizagem e a avaliar suas próprias performances.

Os trabalhos desenvolvidos sobre o tema de avaliação formativa ${ }^{18}$ partem do princípio de que a apropriação pelos alunos dos critérios dos professores, a autogestão dos erros, o domínio dos instrumentos de antecipação e de planificação de ação constituem objetivos prioritários. A partir disso, a aprendizagem dessa auto-avaliação deve ocupar um lugar importante num dispositivo pedagógico adaptado onde a auto-avaliação correta torne-se uma competência primordi- 
al, uma habilidade a ser construída. O auto-controle é percebido como um componente natural da ação considerando-se que uma "instância avaliativa" está presente em cada um de nós, o que nos permite conduzir nossa auto-avaliação.

As nossas próprias pesquisas nos permitiram explicitar algumas caractenísticas necessárias de um documento autocorretivo e salientar alguns resultados relacionados aos efeitos das práticas autocorretivas e auto-avaliativas em sala de aula. Assim, não constatamos diferença significativa quanto à competência, entre os alunos trabalhando num dispositivo que integra as práticas auto-avaliativas e os demais trabalhando num ambiente pedagógico mais tradicional. Entretanto, uma diferença significativa apareceu quanto ao comportamento perante as questões: os alunos do grupo auto-avaliação preferem não responder em caso de dúvida, enquanto que os do grupo tradicional preferem responder correndo o risco de erro. Analisando-se mais minuciosamente as produções do grupo auto-avaliação, observamos que a maneira de usar os documentos de apoio autocorretivos e auto-avaliativos toma-se uma variável interessante. Podemos notar uma competência maior que no grupo tradicional, quando o modo de uso é bem respeitado, porém, essa competência é menor que a do grupo tradicional, no caso contrário.

Durante os anos letivos 88/89 e 89/90 na primeira classe do segundo grau em aula de matemática, conduzimos pesquisas sobre um dispositivo pedagógico baseado em práticas auto-avaliativas, autocorretivas e práticas permitindo uma aprendizagem fundamentada sobre o "tatonnement experimental" 19 do aluno. No fim do ano, fizemos uma avaliação cujo fragmento de questionário seguinte constituía uma parte. Essas questões são destinadas aos alunos.

- Q3 Você pensa que as capacidades de auto-avaliação e de autocorreção devem ser desenvolvidas no contexto escolar? Por quê? Como?

- Q4 Para você, o trabalho desse ano favoreceu ou não o desenvolvimento dessas capacidades?

- Q5 Para você, qual é a validade do julgamento pessoal sobre a sua produção?

- Q6 Quais são as modificações do dispositivo que você propõe?

Considerando-se as questões Q3 e Q4:

Alguns fragmentos de respostas ilustram os argumentos fornecidos:

Celine (89) "eu acho que sim, porque os professores não estarão sempre jun tos da gente para dizer o que a gen te deve fazer. O método utilizado este ano é talvez um pouco rápido. Seria necessário ir progressivamente porque alguns alunos têm dificuldades para se adaptar." 
David (89) "eu acho que sim, eu acho que as capacidades para se autocorrigir e se auto-avaliar devem ser desenvolvidas na escola porque a gente compreende melhor os erros que a gente faz e tenta não errar novamente. Mas, quando a gente se auto-avalia a tendência é de não ter confiança no que faz e então a gente coloca uma nota que é inferior àquela estimada pelo professor"

Christelle (89) “ Não, eu acho que não é a melhor solução, pois é muitas vezes difícil a fazer. Eu acho que as correções devem ser feitas mais pelos professores que pelos alunos que duvidam sobre a validade das respostas. De vez em quando, eu concordo, mas não continuamente."

Denis (90) "Não, pois eu não vejo os meus erros, mesmo quando eu li muitas vezes porque eu permaneço convencido da justeza da minha resposta apesar de que ela seja falsa. Esse método não me ajuda a progredir" Todavia ele respondeu a Q4: "Sim, pois agora sou mais organizado. Os documentos me permitiram de trabalhar com o livro, de repetir os exercícios e de me ajudar a tentar compreen der".

Gael (90) "Não, pois é fastidioso fazer o trabalho de análise dos erros" e ele completa na Q4 "Não, porque sou cabeçudo e não gostava do seu método de ensino, estudava muito pouco e agora não sou capaz de resolver uma equação, enquanto que no ano passado eu achava isso muito fácil. Então não desenvolvi as minhas capacidades, eu até regredi”.

Apesar de serem pouco freqüentes, as respostas negativas puderam nos informar sobre os obstáculos eventualmente gerados por essas práticas pedagógicas.

Analisando-se as respostas da questão Q5 Para você, qual éa validade do julgamento pessoal sobre a sua produção?, observamos os seguintes dados :

\begin{tabular}{|l|l|l|}
\hline $\begin{array}{l}\text { modalidade da resposta } \\
\text { meu julgamento pessoal é... }\end{array}$ & freqüência em junho 89 & freqüência em junho 90 \\
\hline muito pertinente e fiável & 2 & 4 \\
\hline pertinente e fiável & 22 & 24 \\
\hline nem pertinente nem fiável & 2 & 3 \\
\hline de jeito nenhum pertinente ou fiável & 1 & 1 \\
\hline
\end{tabular}

Esses resultados mostram que uma grande maioria de alunos possui uma representação positiva da prática de auto-avaliação deste dispositivo pedagógico. 
Alguns fragmentos de argumentos associados às respostas podem ilustrar essa idéia.

\section{meu julgamento pessoal é muito pertinente e fiável}

Valerie (89) "eu conheço as minhas capacidades"

Muriel (90) "porque quando me auto-avalio, eu não enrolo ninguém, eu não aumento as minhas notas"

\section{meu julgamento pessoal é pertinente e fiável}

Carol (89) "Eu tento me avaliar corretamente, mas com relação ao raciocínio, eu não sei fazer direito"

Emeric (90) "Não pode ser totalmente fiável porque a gente pode pensar que acertou um problema que estava na realidade errado"

\section{meu julgamento pessoal não é nem pertinente e nem fiável}

Valérie (89) "Eu não sei me avaliar muito bem. Eu tenho medo de me superestimar"

\section{fiável}

meu julgamento pessoal não é de jeito nenhum pertinente ou

Sébastien (90) "Eu não consigo detectar os meus erros e por isso eu não posso corrigi-los bem".

Para complementar esta abordagem das representações que os alunos podem ter da auto-avaliação, no fim de um ano escolar, durante o qual eles trabalharam neste dispositivo pedagógico acima, nós relataremos uma síntese das respostas de alunos Marielle e Brahim. A primeira era uma aluna que apresentava dificuldades escolares, enquanto que o segundo caraterizava-se sobretudo como um bom aluno. Para Marielle, "Eu nunca tinha me confrontado com práticas auto-avaliativas. Nenhuma autonomia me foi desenvolvida no primeiro grau. Chegando no segundo grau eu estava habituada a que tudo me fosse dado na boca, e a autonomia que o professor nos deu aqui, me deixou um pouco perdida". Marielle considera entretanto que "as capacidades de autocorreção e auto-avaliação devem ser desenvolvidas na escola" Assim ela propõe: "É preciso ensinar aos alunos do primeiro grau a ter uma certa autonomia, mas paulatinamente. De um ano para outro eu passei de um bebê que tomava mamadeira, a alguém que tinha que fazer tudo por si mesmo. Eu não consegui me organizar, eu me aborreci muito e abandonei tudo". Para Brahim, "Nunca pratiquei a auto-avaliação antes". Ele acredita que essas capacidades devem desenvolvidas "por exercícios como os que nós tínhamos feito em classe, mas eles não devem se restringir a marcar uma casa com X como fizemos durante este ano". Ele considera que o trabalho favoreceu o desenvolvimento "porque agora eu poderia me tornar independente do professor se ele me fornecesse documentos contendo objetivos claros". Brahim pensa que "sua auto-avaliação é muito fiável e pertinente, pois ela baseia-se num questionamento claro". Ele acrescenta que "auto-avaliação deveria partir de objetivos comuns definidos conjuntamente a partir de um debate durante uma aula". 


\section{Conclusão}

Acabar este artigo não implica fechar a problemática da auto-avaliação. Assim, as duas questões seguintes mereceriam ser tratadas em continuidade desse texto num outro momento:

- Pode-se desenvolver a capacidade dos alunos para utilizar uma auto-avaliação pertinente?

- Como se pode organizar um dispositivo pedagógico que favoreça a prática da auto-avaliação, e assim o desenvolvimento da capacidade de autoavaliar-se?

Alguns elementos de respostas já foram evocados acima, mas nosso alvo era mais o de precisar os significados mediante as práticas que o de fornecer condições pedagógicas, validadas por pesquisas, do desenvolvimento da capacidade do aluno de auto-avaliar-se.

Mesmo se a problemática da auto-avaliação faça parte da de avaliação, ela comporta particularidade no que diz respeito à postura do avaliador. Contrariamente à hétero-avaliação, considerada como uma prática em exterioridade com os critérios da objetividade, a auto-avaliação aparece como uma prática em interioridade sujeita à subjetividade, e assim suspeita e geradora de desconfiança. Essa desconfiança é oriunda de um receio de subestimação, mas sobretudo de superestimação de uma competência. Podese perguntar: essa preocupação não seria relacionada à idéia de poder na sala de aula? A introdução de práticas auto-avaliativas colocaria em questão o poder do professor?

Na perspectiva desenvolvida neste artigo, apesar de reconhecer um certo poder do aluno em práticas de avaliação, acreditamos que o poder do professor é não apenas preservado pelas definições dos objetivos e critérios de avaliação, mas também instrumentalizado pelas pesquisas realizadas nessas áreas.

\section{Notas}

1 Smole Kátia Cristina Stocco, A matemática na educação infantil, Porto Alegre: Artes Médicas, 1996, p. 186.

2 Observer pour éduquer, Peter Lang, Berne, 1980.

3 Todo indivíduo em situação de aprendizagem: aluno, estudante, formando, aprendiz, etc.

4 Todo indivíduo em situação de ensino: formador, mestre, etc.

5 Podemos citar os de Henri Pieron nos anos 20 deste século na França.

6 Entretanto, em certos casos onde a nota corresponde a uma contagem efetiva de acertos e erros, teríamos uma variável quantitativa. 
7 Redigindo esse artigo, observei que a definição que dava a essa noção correspondia sobretudo a de auto-avaliação. A definição atual traduz minha nova representação dessa noção.

8 Evaluation et Autonomie: quelques problèmes soulevés parl'auto-évaluation et la pratique auto-corrective en mathématiques.

9 Philosophie de l'éducation, Tome 4, Delagrave 1974, p. 31.

10 Association pour le Développement de la Mesure et de l'Evaluation en Education, colloque 1988, L'auto-évaluation en question(s), Propos pour un débat, Revue Mesure et Evaluation en Education Vol. 13, 31990 PP 5-26.

11 Evaluation fondée sur les objectifs: une approche metacognitive, op.cit. communication au colloque ADMEE 1988 Bruxelles.

12 Analyse du domaine des croyances reliées á l'évaluation des apprentissages, Revue Mesure et Evaluation en Education Vol 13, 11990 PP 5-28.

13 L'auto-évaluation, instrument de motivation pour les mathématiques, mémoire professionnel sous la direction de Jean-Claude Régnier, soutenu á l 'IUFM de Bourgogne, mai 1992.

14 Travail Autonome et Disciplines scientifiques en lycée (Tome2) -1991.

15 L'évaluation en formation, PUF, 1985.

16 Freedom from external evaluation (1972) citado por Leselbaum Autonomie et Autoévaluation Economica1982.

17 Self-control in the classroom, Review of Educational Research,4, 1976pp 648-652.

18 Pour construire un dispositif d'évaluation formatrice, Nunziati, G, Revue Cahiers Pédagogiques, 280, janv 1990, pp 47-64.

19 Segundo a expressão francesa em pedagogia Freinet.

\section{Referências bibliográficas}

ADMEE - Association pour le Développement de la Mesure et de l'Evaluation en Education, colloque 1988, Láuto-évaluation en question(s), Propos pour un débat, Revue Mesure et Evaluation en Education, vol 13, 3, 1990, Bruxelles. BARBIER, J. M.. 1985. L'évaluation en formation, PUF, Paris.

DE KETELE. 1980. Observer pour éduquer, Peter Lang, Berne.

DUBOUX. 1992. L'Auto-évaluation, instrument de motivation pour les mathématiques, "mémoire professionnel" orientada por Jen-Claude Régnier, IUFM de Bourgogne.

FONTAINE \& TRAHAN. 1990. Analyse du domaine des croyances reliées à l'évaluation des apprentissages. Revue Mesure et Evaluation en Education, vol. 13, 3, 1990, Bruxelles. 
LAVEAULT \& FOURNIER. 1990. Evaluation fondée sur les objectifs: une approche metacognitive, Revue Mesure et Evaluation en Education, vol. 13, 3, 1990, Bruxelles.

LEIF, J. 1974. Philosophie de l'Education, tomo 4, Delagrave.

Mc LAUGHLIN. 1976. Self-control in the classroom, Review of Educational Research, 4,

NUNZIATI, G., 1990. Pour construire un dispositif d'évaluation formatrice, Revue Cahiers Pédagogiques, 280, jan. 1990.

REGNIER, J-C. 1980. Elaboration d'un livret auto-correctif: étude préliminaire par un questionnaire sur l'équation du second degré en classe de seconde TI et projet de livret auto-correctif, D.E.A de mathématiques, Nancy, IREMUniversité.

REGNIER, J.C. 1982. Documents autocorrectifs en mathématique: quelques propositions d'élaboration et effects didactiques, IMAG, Grenoble.

REGNIER, J-C. 1983. Etude didactique d'un test autocorrectif en trigonométrie, Thèse de doctorat de mathématiques, mention didactique, IREM-Université, Strasbourg.

REGNIER, J-C. 1983. Evaluation et Autonomie, Strasbourg, IREM-Université. REGNIER, J-C. 1983. Assaig de pràctica de la Pedagogia Freinet a segon curs de lycée, Perspectiva Escolar, (79), 1983, Rosa Sensat, Barcelona.

REGNIER, J-C. Evaluation et Autonomie: quelques propositions soulevés par l'auto-évaluation et la pratique auto-corretive en mathématiques, L'Educateur, (1), 1984, ICEM-Pédagogie Freinet/ PEMF.

REGNIER, J-C. 1986. Étude d'une Tentative de formation à l'autoévaluation d'éleves de classe de seconde de Lycée, dans le cadre de l'enseignemente des mathématiques: t. 1: étude théorique, t. 2: annexe documentaire, t. 3: recueil de données. D.E.A de Sciences de l'Education, Université de Lyon 2.

REGNIER, J-C, 1991. Autonomie et travail personnel dans l'enseignement des disciplines scientifiques en Lycée: Témoignage d'un travail conduit sur une année scolaire, Paris: MEN-DLC, Dijon: C.R.D.P.

SMOLE, Kátia Cristina Stocco. 1996. A matemática na educação infantil, Artes médicas, Porto Alegre. 